\title{
Dependence, plans to quit, quitting self-efficacy and past cessation behaviours among menthol and other flavoured cigarette users in Europe: The EUREST-PLUS ITC Europe Surveys
}

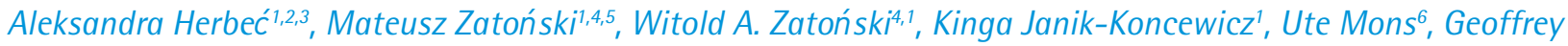 \\ T. Fong ${ }^{7,8,9}$, Anne C. K. Quah ${ }^{7}$, Pete Driezen ${ }^{7}$, Tibor Demjén ${ }^{10}$, Yannis Tountas ${ }^{11}$, Antigona C. Trofor ${ }^{12,13}$, Esteve

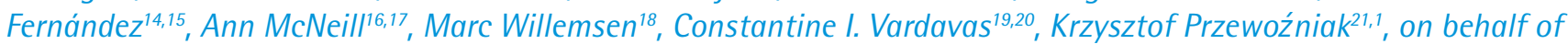 \\ the EUREST-PLUS consortium*
}

\section{ABSTRACT}

INTRODUCTION This study characterises smoking and cessationrelated behaviours among menthol and other flavoured cigarette users in Europe prior to the implementation of the European Tobacco Products Directive (TPD) ban on the sale of flavoured cigarettes.

METHODS An analysis of cross-sectional data from the 2016 EUREST-PLUS ITC Europe Surveys was conducted among a sample of 10760 adult smokers from eight European Union Member States. Respondents were classified as menthol, other flavoured, unflavoured, or no usual flavour cigarette users and compared on smoking and cessation behaviours and characteristics. Data were analysed in SPSS Complex Samples Package using bivariate and multivariate regression analyses adjusted for sociodemographic characteristics, dependence, and country.

RESULTS In bivariate analyses, cigarette flavour was significantly associated with all outcomes $(\mathrm{p}<0.001)$. After adjusting for sociodemographic characteristics, these associations attenuated but remained significant and in the same direction for dependence, self-efficacy, plans to quit, past quit attempts, and ever e-cigarette use. In fully adjusted models, compared to smokers of non-flavoured cigarettes, menthol smokers were less likely to smoke daily ( $\mathrm{AOR}=0.47,95 \% \mathrm{CI}$ : 0.32-0.71), smoke within 30 min of waking $(0.52,0.43-0.64)$, consider themselves addicted (0.74,0.59-0.94), and more likely to have ever used e-cigarettes (1.26,1.00-1.57); other flavoured cigarette smokers were less likely to smoke daily $(0.33,0.15-0.77)$, and have higher self-efficacy $(1.82,1.20-2.77)$; no usual flavour smokers were less likely to smoke daily $(0.34,0.22-0.51)$, smoke within 30 min of waking $(0.66,0.55-0.80)$, consider themselves addicted $(0.65,0.52-0.78)$, have ever made a quit attempt $(0.69,0.58-$ $0.84)$, have ever used e-cigarettes $(0.66,0.54-0.82)$, and had higher self-efficacy $(1.46,1.19-1.80)$.

\section{AFFILIATION}

1 Health Promotion Foundation (HPF), Warsaw, Poland

2 Department of Behavioural Science and Health, University College London, London, United Kingdom 3 Centre for Behaviour Change, Clinical, Educational and Health Psychology, University College London, United Kingdom 4 European Observatory of Health Inequalities, President Stanisław Wojciechowski State University of Applied Sciences, Kalisz, Poland

5 Tobacco Control Research Group, Department for Health, University of Bath, Bath, United Kingdom 6 Cancer Prevention Unit and WHO Collaborating Centre for Tobacco Control, German Cancer Research Center (DKFZ), Heidelberg, Germany 7 Department of Psychology, University of Waterloo (UW), Waterloo, Canada

8 School of Public Health and Health Systems, University of Waterloo (UW), Waterloo, Canada 9 Ontario Institute for Cancer Research, Toronto, Canada

10 Smoking or Health Hungarian Foundation (SHHF), Budapest, Hungary

11 National and Kapodistrian University of Athens (UoA), Athens, Greece

12 University of Medicine and Pharmacy 'Grigore T.

Popa' lasi, lasi, Romania

13 Aer Pur Romania, Bucharest, Romania

14 Tobacco Control Unit, Catalan Institute of Oncology (ICO), and Tobacco Control Research Group, Bellvitge Biomedical Research Institute (IDIBELL), Catalonia, Spain

15 School of Medicine and Health Sciences, University of Barcelona, Catalonia, Spain 16 UK Centre for Tobacco and Alcohol Studies, London, United Kingdom

17 National Addiction Centre, King's College London, London, United Kingdom

18 Department of Health Promotion, Maastricht University, Maastricht, the Netherlands

19 European Network for Smoking and Tobacco Prevention (ENSP), Brussels, Belgium

20 University of Crete (UoC), Heraklion, Greece

21 Maria Skłodowska-Curie Institute - Oncology

Center, Warsaw, Poland 
CONCLUSIONS Smokers of different cigarette flavours in Europe differ on smoking and cessation characteristics. The lower dependence of menthol cigarette smokers could lead to greater success rates if quit attempts are made, however cross-country differences in smoking behaviours and quitting intentions could lead to the TPD ban on cigarette flavours having differential impact if not accompanied by additional measures, such as smoking cessation support.
CORRESPONDENCE TO

Aleksandra Herbeć. Centre for Behaviour Change, University College London (UCL), 1-19 Torrington Place, London, WC1E 7HB, United Kingdom. E-mail: a.herbec@ucl.ac.uk

ORCID ID: https://orcid.org/0000-0002-3339-7214

KEYWORDS

menthol cigarettes, Europe, smoking cessation, attitudes, cross-sectional

Received: 5 March 2019

Revised: 24 July 2019

Accepted: 26 July 2019

\section{INTRODUCTION}

The 2014 European Tobacco Product Directive (TPD $)^{1}$ introduced a ban on the sales of menthol and flavoured cigarettes (MFCs) in the European Union member states (EU MS), with a transitional period for menthol cigarettes until May $2020^{2}$. This ban aims to limit appeal and attractiveness of such cigarettes, particularly to young people, and could constitute an important opportunity to promote cessation among MFC smokers ${ }^{3}$. To date, most studies of menthol cigarette smokers have been conducted in the United States $^{4-10}$, with little research available on European smokers ${ }^{11}$. The International Tobacco Control (ITC) Project conducted in eight European countries offers an opportunity to study the characteristics and behaviours of MFC smokers ${ }^{12}$. An earlier study using this sample has shown important differences in the prevalence of flavoured cigarette use between different European countries, as well as considerable differences in attitudes towards tobacco control policies between users of different cigarette flavours ${ }^{13}$. The present study extends this analysis to characterise the smoking and past cessation behaviours, motivation and self-efficacy to quit among MFC smokers in Europe.

A considerable minority of smokers use flavoured cigarettes, with menthol being the most popular ${ }^{13-15}$. The prevalence of menthol cigarette smoking in the United States among past 30-day smokers in 2012-2014 was $39 \%^{5}$, with the rates being highest among African-American smokers ${ }^{16}$. Prevalence of MFC smokers in Europe varies considerably across countries, and ranges from $6 \%$ in Spain to $15 \%$ in the $\mathrm{UK}^{13}$. MFCs are also more commonly used among younger smokers, less-established or novice smokers, and those who are experimenting with smoking ${ }^{14,17}$. MFCs have also been considered a gateway product, especially as some research suggests that switching from menthol to non-menthol cigarettes is more common than switching from non-menthol to menthol cigarettes $^{18}$. Furthermore, prior research conducted in the US has pointed to higher levels of cigarette dependence among menthol cigarette smokers than unflavoured cigarette smokers ${ }^{19-21}$, although some studies have found no difference ${ }^{22}$.

The popularity of MFCs has been attributed to several factors. Flavouring, and especially menthol that has cooling and anaesthetic effects, can improve the smoking experience by masking or limiting some of the negative sensations associated with smoking, such as burning, throat pain, and cough ${ }^{14}$. The tobacco industry has been manipulating the menthol content of cigarettes to promote smoking initiation and sustain nicotine dependence ${ }^{23,24}$, and has actively advertised menthol brands, especially among ethnic groups and younger smokers in the US ${ }^{25}$. Analysis of tobacco industry research has also suggested that while younger and less experienced smokers may prefer menthol cigarettes due to the less harsh smoking experience, more dependent and experienced smokers may seek the menthol flavours for their strong sensory qualities ${ }^{26}$. Finally, menthol in cigarettes may improve nicotine intake, thus helping to maintain high enough nicotine levels among smokers who cannot afford to purchase and smoke more cigarettes per day ${ }^{19}$.

The aim of the present study was to crosssectionally assess MFC smokers in eight of the EU MS on cigarette dependence, plans to quit and quitting 
self-efficacy, and past cessation behaviours prior to the implementation of the TPD. The findings could help inform tobacco control policies and smoking cessation campaigns to accompany the TPD ban on the sale of flavoured and menthol cigarettes.

\section{METHODS}

\section{Design}

This study was conducted within the context of the European Commission Horizon 2020 funded study entitled European Regulatory Science on Tobacco: Policy implementation to reduce lung diseases (EUREST-PLUS-HCO-06-2015). Crosssectional analysis was conducted of data from current smokers aged $\geq 18$ years from eight European EU MS participating in the ITC Project ${ }^{27}$. The countries included in the study were: Germany, Greece, Hungary, Poland, Romania and Spain (part of the EUREST-PLUS ITC Project, later referred to as $\left.6 \mathrm{E}^{28-30}\right)$, the Netherlands ${ }^{31,32}$, and England ${ }^{30,33,34}$. The survey in $6 \mathrm{E}$ was conducted using computer-assisted personal interviews (CAPI) and in the Netherlands and England through a web survey.

\section{Sampled populations}

The total sample analysed in this study comprised 10760 adult smokers from the eight European countries $(n=6011$ from the six countries of the ITC $6 \mathrm{E}$ Survey, $\mathrm{n}=3536$ from ITC England, and $n=1213$ from ITC Netherlands, see details below). This sample was aged $43.2(\mathrm{SE}=0.19)$ years on average, $43.5 \%$ female, and $14.0 \%$ had higher education (for a detailed description of the sample, including the breakdown of prevalence of smoking of different cigarette flavours across sociodemographic groups and countries, see Zatoński et al. ${ }^{13}$ in the same supplement).

The ITC 6E Survey was conducted between 18 June 2016 and 12 September $2016^{12,28}$. The surveyed sample comprised a nationally representative sample of adult cigarette smokers aged $\geq 18$ years (about 1000 participants in each country). Sampling was done using geographical strata determined by Nomenclature of Territorial Units for Statistics (NUTS) regions crossed with degree of urbanization (urban, intermediate, rural). Approximately 100 area clusters were sampled in each country (allocated to strata proportionally to population size for people aged $\geq 18$ years), with the aim of recruiting 10 adult smokers per cluster. Within each cluster, household addresses were sampled using a random walk design. One randomly selected male smoker and one randomly selected female smoker were chosen for interview from a sampled household, where possible. Screening of households continued until the required number of smokers from the cluster had been interviewed.

Data from England was nationally representative and came from Wave 1 of the ITC Four Country Smoking and Vaping Survey conducted between July and November $2016^{30,33,34}$. Further details on the survey methodology are available elsewhere ${ }^{13,35}$. Only current adult smokers aged $\geq 18$ years were included in the present analysis $(\mathrm{n}=3536)$.

Data for Wave 10 of the ITC Netherlands (NL) Survey ${ }^{31,32}$ were collected between November and December 2016. Respondents were 1696 adults aged $\geq 15$ years recruited as cigarette smokers, who were part of a probability-based web database ${ }^{36}$. The nationally representative sample included 1318 respondents who had also participated in Wave 9 and 378 new respondents recruited to replenish dropouts ${ }^{37}$. Only current adult (aged $\geq 18$ years) smokers were included in the analysis $(n=1213)$.

\section{Measurements}

Cigarette flavour

Participants were asked if they had a usual cigarette brand and if they did, they were asked about the flavour of their usual brand: just tobacco ('unflavoured tobacco'), tobacco and menthol ('menthol'), or 'other flavoured'. A final category of 'no usual flavour' included all remaining participants who either: a) reported having no usual brand, b) refused to answer or answered 'don't know' to the question about having a usual brand, or c) reported having a usual brand but who did not provide information on the flavour of that brand.

\section{Smoking dependence}

Dependence was assessed using: i) smoking daily vs non-daily, ii) cigarettes smoked per day, iii) time to first cigarette, and iv) Heaviness of Smoking Index (HIS), scores ranging $0-6$, with $\geq 4$ suggesting greater dependence ${ }^{38}$; as well as self-perceived addiction levels ('How addicted are you to cigarettes?' with response 'not at all', 'yes-somewhat addicted', or 'yesvery addicted'). 


\section{Motivation to quit}

Respondents were asked:

'Are you planning to quit smoking? within the next month/within the next 6 months/beyond 6 months/ not at all/don't know'. In the logistic regression the responses were dichotomised to 'planning to quit in the next 6 months' vs 'all other' ${ }^{39-41}$.

\section{Quitting self-efficacy}

This involved two questions ${ }^{42}$ that assessed:

$1)$ confidence to quit ('If you decided to give up smoking completely in the next 6 months, how sure are you that you would succeed? Not at all sure or slightly sure/moderately sure/very sure or extremely sure' $)^{43,44}$. In the logistic regression, the answers were dichotomised to 'very or extremely sure' vs 'all other'; and

2 ) perceived difficulty of quitting ('How difficult would it be for you to quit smoking if you wanted to? not at all/slightly/moderately/very/extremely' ${ }^{45,46}$. For the purpose of logistic regression the answers were dichotomised to "not at all or slightly vs all other'.

\section{Prior quit attempts and use of cessation aids}

Data were collected on: i) having ever made a quit attempt (yes/no), and ii) having made a quit attempt in the past 12 months (yes/no). Participants who reported having made a quit attempt were asked about the use of any cessation aids during the last quit attempt (yes/no; combining any of nicotine products, medication on prescription, face-to-face support, quitline, cessation services, online support, and e-cigarettes). Due to only very few cases of refused to answer/don't know or missing data for these variables, the data are reported as 'yes' vs 'all other'. All participants were also asked about 'ever hearing about e-cigarettes', and those who responded affirmatively $(n=8870)$ were asked about having ever used e-cigarettes; for the present analysis the variable on ever e-cigarette use was dichotomised into yes/no (with no including all other answers and participants who had not heard about e-cigarettes).

\section{Sociodemographics (confounders and covariates)}

The following sociodemographic variables were assessed: country, sex (male/female), age group (18$24 / 25-39 / 40-54 / \geq 55$ years), educational attainment (derived and standardised variable across countries: low/medium/high $)^{47}$.

\section{Statistical analysis}

For the main analysis, data from all countries were pooled and analysed together using the Complex Samples package in SPSS 23.00 that accounted for the sampling procedure in each country. Sampling weights were also used to ensure results represent the population of smokers in each country. Missing data were not imputed (for sociodemographic and HSI variables, the missing data ranged from $0 \%$ for age and $7.2 \%$ for HSI; for independent variables missing data ranged from $0 \%$ for daily smoking to $17.5 \%$ for ever e-cigarette use). 'Refused to answer/don't know' responses to individual questions were included in the 'no' category for dichotomous variables. Bivariate analyses (crosstabs for categorical and general linear models for continuous variables) compared smokers of different cigarette flavours on sociodemographic, smoking, quitting, and attitudinal variables. We present percentages and means and $95 \%$ confidence intervals (CI). Unless indicated, weighted number of participants are provided, rounded up to the nearest whole number.

We conducted unadjusted and adjusted logistic regression models to assess the relationship between cigarette flavour and categorical outcomes of interest. In all analyses, smokers of unflavoured tobacco were the reference group. The dependent variables were dichotomised outcomes of interest (being a daily smoker vs non-daily; smoking within the first 30 min of waking vs all other; HSI of $\geq 4$ vs lower; considering oneself to be very addicted vs all others; ever having made a quit attempt vs not; having made a quit attempt in the past 12 months vs not; having used quit aids and e-cigarettes in the last quit attempt vs not; planning to quit in the next 6 months vs not; being very or extremely sure one could quit vs not; expecting quitting to be very or extremely difficult vs not. Findings from three models are reported: unadjusted (Model 1), partially adjusted for sociodemographic characteristics and dependence level (categorical variables: sex, age group, education level, and continuous variable HSI; Model 2), and fully adjusted with country variable added as an additional adjustment (Model 3). We report associated odds ratios (ORs) and 95\% confidence intervals (95\% 
CIs). The multivariable regression models assessed main effects, with all variables entered together. To adjust for multiple comparisons and familywise errors (about 10 tests for related outcomes), we used the Sidak correction to adjust alpha to $<0.005$ as a threshold for statistical significance.

\section{RESULTS}

\section{Participants}

The majority of smokers $(88.1 \%)$ had a preferred cigarette brand. Unflavored tobacco was smoked by $77.4 \%$, menthol by $7.4 \%$, other flavoured by $2.9 \%$, and $12.3 \%$ had no usual flavour. Table 1 presents results of

Table 1. Smoking and cessation behaviour among smokers of different cigarette flavours in ITC European countries

\begin{tabular}{|c|c|c|c|c|c|c|}
\hline Behaviour & Menthol & $\begin{array}{l}\text { Other } \\
\text { flavoured }\end{array}$ & $\begin{array}{l}\text { Unflavoured } \\
\text { tobaceo }\end{array}$ & $\begin{array}{l}\text { Vo usual } \\
\text { Tlavour }\end{array}$ & Total & $p$ \\
\hline \multicolumn{7}{|l|}{ Cigarette dependence } \\
\hline Smoking daily \% $(95 \% \mathrm{CI})$ & $78.8(74.8-82.3)$ & 89.3 (83.3-93.3) & $94.0(93.3-94.6)$ & 79.8 (76.7-82.6) & $90.9(90.2-91.7)$ & $<0.001$ \\
\hline \multicolumn{7}{|l|}{ Cigarette smoked/day, \% (95\% Cl) } \\
\hline$\leq 10$ & $64.5(60.4-68.4)$ & $36.7(29.6-44.5)$ & $37.3(36.0-38.8)$ & $47.0(43.1-51.2)$ & $40.5(39.3-41.8)$ & $<0.001$ \\
\hline $11-20$ & $30.7(27.0-34.6)$ & $49.6(41.6-57.6)$ & $50.0(48.6-51.3)$ & $39.1(35.3-43.0)$ & $47.2(46.0-48.5)$ & \\
\hline $21-30$ & $2.9(1.9-4.5)$ & $7.2(4.6-11.2)$ & $9.1(8.3-9.9)$ & $9.4(7.4-11.8)$ & $8.6(7.9-9.3)$ & \\
\hline$\geq 31$ & $1.8(1.0-3.3)$ & $6.4(3.4-11.9)$ & $3.6(3.1-4.2)$ & $4.4(3.2-6.1)$ & $3.7(3.2-4.2)$ & \\
\hline \multicolumn{7}{|l|}{$\begin{array}{l}\text { Minutes to first cigarette, } \\
\%(95 \% \mathrm{Cl})^{\mathrm{b}}\end{array}$} \\
\hline$>60$ & 36.2 (31.7-40.9) & $19.3(13.1-27.3)$ & $18.0(16.9-19.1)$ & $25.2(21.7-29.0)$ & $20.1(19.0-21.2)$ & $<0.001$ \\
\hline $31-60$ & $16.7(13.6-20.4)$ & $17.7(13.0-23.7)$ & $16.2(15.2-17.3)$ & $16.8(14.0-20.0)$ & $16.4(15.4-17.4)$ & \\
\hline $6-30$ & $33.9(29.6-38.4)$ & $46.7(39.4-54.1)$ & $45.1(43.6-46.7)$ & $36.7(32.7-40.1)$ & $43.5(42.0-44.8)$ & \\
\hline$\leq 5$ & $13.2(10.3-16.8)$ & $16.3(10.0-25.6)$ & $20.7(19.4-22.1)$ & $21.7(18.5-25.3)$ & $20.2(19.0-21.4)$ & \\
\hline HSI, Mean $(95 \% \mathrm{CI})^{\mathrm{c}}$ & $1.70(1.56-1.85)$ & $2.49(2.22-2.75)$ & $2.50(2.46-2.55)$ & $2.36(2.21-2.50)$ & $2.43(2.39-2.47)$ & $<0.001$ \\
\hline $\begin{array}{l}\text { Consider themselves very } \\
\text { addicted, } \%(95 \% \mathrm{Cl})\end{array}$ & $28.7(25.0-32.7)$ & $34.6(26.9-43.2)$ & $44.0(42.5-45.6)$ & $30.5(27.4-33.8)$ & $41.0(39.6-42.3)$ & $<0.001$ \\
\hline $\begin{array}{l}\text { Plans and attitudes on } \\
\text { quitting }\end{array}$ & & & $\%(95 \% \mathrm{Cl})$ & & & \\
\hline $\begin{array}{l}\text { Plans to quit in the next } 6 \\
\text { months }^{d}\end{array}$ & $31.1(27.1-35.5)$ & $17.5(12.2-24.5)$ & $20.3(19.2-21.4)$ & $20.4(17.7-23.4)$ & $21.0(20.0-22.0)$ & $<0.001$ \\
\hline \multicolumn{7}{|l|}{ Plans to quit in the future } \\
\hline In the next month & $12.9(10.0-16.4)$ & $3.1(1.5-6.1)$ & $6.5(5.8-7.2)$ & $7.7(5.9-10.0)$ & $7.0(6.4-7.7)$ & $<0.001$ \\
\hline Next 6 months & $18.3(15.1-22.0)$ & $14.4(9.7-21.0)$ & $13.8(12.9-14.8)$ & $12.7(10.6-15.0)$ & $14.0(13.2-14.9)$ & \\
\hline Beyond 6 months & 33.7 (29.8-37.9) & $33.3(25.8-41.8)$ & $31.4(30.0-32.8)$ & 30.5 (27.4-33.9) & $31.5(30.3-32.8)$ & \\
\hline Not planning to quit & $27.0(23.3-31.1)$ & $42.7(32.9-53.1)$ & $40.6(39.1-42.1)$ & $39.6(35.8-43.7)$ & $39.6(38.2-40.9)$ & \\
\hline Don't know & $8.1(6.1-10.6)$ & $6.5(3.1-13.0)$ & $7.7(7.0-8.5)$ & $9.5(7.3-12.3)$ & $7.9(7.2-8.7)$ & \\
\hline
\end{tabular}

SEF: confidence to quit (sure would succeed at quitting) ${ }^{\mathrm{e}}$ Not at all or slightly sure Moderately sure Very or extremely sure

$50.3(45.8-54.8)$ $30.6(26.6-35.0)$ $19.1(15.8-22.9)$

$62.5(55.1-69.4)$ $21.6(16.5-27.8)$ $15.9(10.8-22.9)$
$63.8(62.4-65.1)$ $23.2(22.0-24.5)$

$13.0(12.0-14.0)$
$52.6(48.5-56.2)$ $27.3(23.9-31.0)$

$20.3(17.3-23.8)$
$61.4(60.1-62.2)<0.001$ $24.2(23.1-25.4)$ $14.4(13.5-15.4)$

SEF: perceived difficulty of quitting (how hard to quit completely) ${ }^{f}$

Not at all or slightly

Moderately

Very or extremely

History of quitting

Ever tried to quit

$\mathrm{QA}$ in the past 12 months*

Cessation aids in last $Q A^{*}$

Ever used e-cigarettes

$27.5(23.8-31.6)$
$20.3(17.0-24.1)$
$52.2(47.8-56.5)$
$70.3(66.2-74.1)$
$42.1(37.8-46.5)$
$29.1(24.6-34.0)$
$53.3(49.0-57.6)$

$29.3(22.1-37.8)$ $22.2(17.3-28.0)$ 48.5 (40.4-56.5)

$59.8(52.9-66.4)$

$23.8(17.8-31.2)$

$23.2(16.1-32.4)$

$33.9(26.6-42.0)$
$20.0(19.0-21.4)$ $20.8(19.6-22.1)$ $59.0(57.6-60.5)$ $\%(95 \% \mathrm{Cl})$

$64.0(62.4-65.6)$

27.7 (26.4-28.9)

20.2 (18.8-21.6)

38.5 (37.0-39.9)
$29.8(26.4-33.3)$ $25.6(22.1-29.3)$ 44.7 (40.9-48.6) 54.1 (49.9-58.2) $24.3(21.3-27.6)$ $19.3(16.0-23.2)$ 29.8 (26.4-33.4)

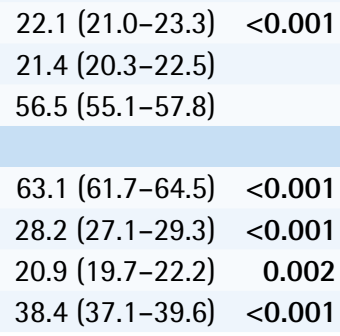

a Missing from 1.1\%; b Missing from 6.7\%; c Missing among 7.2\%; d 7.9\% of don't know and 0.1\% refused to answer were incorporated into 'not planning to quit'; e Missing from 4.1\%; f Missing from 1.8\%; HSI: Heaviness of Smoking Index; SEF: Self-efficacy; QA: quit attempt; *Assessed among smokers who ever made a quit attempt, cessation aids included: behavioural support, use of websites, pharmacotherapy, and e-cigarettes. 
bivariate comparisons of smokers of different cigarette brand flavours on cigarette dependence, as well as on smoking and quitting behaviours and attitudes.

\section{Dependence levels}

The great majority of smokers smoked cigarettes daily $(90.9 \%)$, and had moderate HSI levels (mean=2.4) (Table 1). A large minority $(41.0 \%)$ considered themselves to be very addicted. In the unadjusted analyses, the flavour of the preferred cigarette brand was significantly associated with all measures of cigarette dependence (Tables 1 and 2, unadjusted Model 1). Menthol cigarette smokers had the lowest levels of daily smoking, a lower HSI index, were less likely to smoke within $30 \mathrm{~min}$ of waking, and considered themselves less addicted. Smokers of other flavoured cigarettes had a dependence profile more similar to that of unflavoured tobacco smokers. In the fully adjusted analysis (Table 2, Model 3) with unflavoured tobacco being the reference group, menthol, other flavoured, and no usual flavour cigarette users were significantly less likely to smoke daily $(\mathrm{AOR}=0.47,95 \%$ CI: 0.32-0.71; 0.33, 0.15-0.77; $0.34,0.22-0.51$, respectively). Menthol and no usual flavour smokers were less likely to smoke within 30 min of waking ( $\mathrm{AOR}=0.52,95 \% \mathrm{CI}$ : $0.43-0.64 ; 0.66$, $0.55-0.80$, respectively) or to consider themselves to be very addicted to cigarettes $(\mathrm{AOR}=0.74,95 \% \mathrm{CI}$ : $0.59-0.94 ; 0.65,0.52-0.78$, respectively).

\section{Plans and self-efficacy to quit}

A considerable proportion (39.6\%) of smokers were not planning to quit, and only $21.0 \%$ planned to quit in the next 6 months. The majority had low quitting self-efficacy $(61.4 \%$ were not at all or slightly sure they could succeed at quitting and $56.5 \%$ believed quitting would be very or extremely hard) (Table
1). In the bivariate analysis, cigarette flavour was significantly associated with plans and self-efficacy to quit, with unflavoured tobacco users having the lowest self-efficacy and menthol tobacco users having more immediate plans to quit (Table 1; Model 1 in Table 2 ). In the fully adjusted analysis (Table 2, Model 3), cigarette flavour was not significantly associated with plans to quit. Cigarette flavour remained significantly predictive of self-efficacy at quitting, with no usual flavour smokers having higher odds for higher selfefficacy for being sure they could quit $(\mathrm{AOR}=1.40$, 95\% CI: $1.17-1.68$ ) or not considering quitting as difficult $(\mathrm{AOR}=1.46,95 \%$ CI: 1.19-1.80). Other flavoured cigarette users had higher odds of expecting quitting not to be difficult (AOR=1.81, 95\% CI: 1.20 $2.77)$.

\section{Prior cessation behaviour}

Over $63 \%$ of smokers had ever made a quit attempt, $28.2 \%$ had made a quit attempt in the past 12 months, and $20.9 \%$ had used some cessation aids (except e-cigarettes) during their last quit attempt, and $38.4 \%$ had ever tried e-cigarettes (Table 1). In the unadjusted and partially adjusted models (Table 1 , Models 1 and 2 in Table 2), cigarette flavour was significantly associated with these prior cessation behaviours. These behaviours were significantly more prevalent among menthol smokers in comparison to unflavoured tobacco smokers. The relationships between cigarette flavour and cessation behaviours were attenuated once country was controlled in the fully adjusted models (Model 3, Table 2); no usual flavour smokers were less likely to have ever made a quit attempt (AOR=0.69, 95\% CI: $0.58-0.84)$ or have ever used e-cigarette ( $\mathrm{AOR}=0.66,95 \% \mathrm{CI}: 0.54-0.82)$. Menthol cigarette users were more like to have ever used e-cigarettes $(\mathrm{AOR}=1.26,95 \% \mathrm{CI}: 1.00-1.57)$.

Table 2. Flavour of cigarettes and smoking and cessation profile (Ref. 'unflavoured tobacco')

\begin{tabular}{|c|c|c|c|c|c|c|}
\hline Outcome of interest & $\begin{array}{c}\text { Vodel I } \\
\text { OR }\left(95^{\circ} \% \text { CI }\right)\end{array}$ & $p^{*}$ & $\begin{array}{c}\text { Model } 2^{a} \\
\text { IOR }\left(95^{\circ} \% \text { CI) }\right.\end{array}$ & $p^{*}$ & $\begin{array}{c}\text { Vodel } 3^{b} \\
\text { AOR }\left(95^{\circ} \% \text { CI) }\right.\end{array}$ & $p^{*}$ \\
\hline \multicolumn{7}{|l|}{ Cigarette dependence } \\
\hline \multicolumn{7}{|l|}{ Smoking daily vs not ${ }^{\mathrm{c}}$} \\
\hline Menthol & $0.24(0.19-0.31)$ & $<0.001$ & $0.37(0.25-0.54)$ & $<0.001$ & $0.47(0.32-0.71)$ & $<0.001$ \\
\hline Other flavoured & $0.53(0.31-0.91)$ & & $0.49(0.23-1.00)$ & & $0.33(0.15-0.77)$ & \\
\hline No usual flavour & $0.25(0.20-0.31)$ & & $0.41(0.29-0.60)$ & & $0.34(0.22-0.51)$ & \\
\hline
\end{tabular}


Table 2. Continued

\section{Outcome of interest}

Cigarette dependence

Smoke within 30 min of waking ${ }^{d}$

Menthol

Other flavoured

No usual flavour

HIS score $\geq 4^{c}$

Menthol

Other flavoured

No usual flavour

Consider themselves very addicted

Menthol

Other flavoured

No usual flavour

Quitting plans and self-efficacy

Plan to quit in the next 6 months vs all other

Menthol

Other flavoured

$1.82(1.47-2.25)$

$0.82(0.52-1.26)$

$1.03(0.85-1.25)$

$<0.001$

$1.32(1.05-1.68)$

$0.76(0.50-1.16)$

$0.90(0.73-1.12)$

0.032

$1.05(0.82-1.35)$

0.978

No usual flavour

Very or extremely sure they could quit vs all other

Menthol

Other flavoured

$1.74(1.44-2.10)$

$1.06(0.77-1.45)$

$<0.001$

$1.20(0.97-1.48)$

$0.95(0.69-1.30)$

$1.40(1.17-1.68)$

0.002

$1.11(0.90-1.38)$

0.003

$1.60(1.36-1.89)$

$0.99(0.72-1.36)$

$1.40(1.17-1.68)$

Expect quitting to be not at all or

slightly difficult vs all other

Menthol

Other flavoured

$1.50(1.23-1.85)$

$1.65(1.12-2.43)$

$<0.001$

$1.03(0.81-1.31)$

1.87 (1.19-2.92)

$<0.001$

$1.28(1.00-1.65)$

$1.82(1.20-2.77)$

$1.48(1.21-1.82)$

$1.46(1.19-1.80)$

Prior cessation behaviour

Ever made a $\mathrm{QA}$

$1.68(1.40-2.01)$

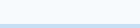

0.001
Menthol

Other flavoured

No usual flavour

$\mathrm{QA}$ in the past 12 months

Menthol

Other flavoured

No usual flavour

Last $\mathrm{QA}$ : used any cessation support $\mathrm{c}^{\mathrm{c}}$

Menthol

Other flavoured

No usual flavour

$1.33(1.09-1.62)$

$0.84(0.63-1.12)$

$0.66(0.56-0.79)$

$1.90(1.57-2.29)$
$0.82(0.56-1.19)$
$0.84(0.70-1.01)$

1.62 (1.27-2.07)

$1.20(0.75-1.91)$

0.95 (0.74-1.22)

Ever used e-cigarettes

Menthol

Other flavoured

No usual flavour

$1.83(1.52-2.20)$

$\begin{aligned}<0.001 \quad & 1.16(1.03-1.32) \\ 1.21(1.03-1.42) & <0.001 \\ & 1.28(0.78-2.09)\end{aligned}$

$1.13(0.91-1.40)$

$0.97(0.69-1.36)$

$0.69(0.58-0.84)$

$<0.001$

1.45 (1.18-1.78)

0.77 (0.54-1.09)

$<0.001$

$1.20(0.98-1.50)$

$0.92(0.64-1.32)$

0.73 (0.60-0.89)

0.81 (0.66-1.00)

0.001

$1.35(1.03-1.77)$
$1.08(0.69-1.71)$
$0.81(0.61-1.07)$

0.043

$1.01(0.75-1.36)$

$1.35(0.83-2.17)$

$1.06(0.79-1.42)$

$<0.001$

1.56 (1.28-1.92)

$0.85(0.58-1.24)$

0.57 (0.47-0.70)
$1.26(1.00-1.57)$

$1.12(0.73-1.74)$

$0.66(0.54-0.82)$

0.045

0.669

AOR: adjusted odds ratio; HSI: Heaviness of Smoking Index; QA: quit attempt; a Model 2: adjusted for sex, age, education, and HSI; b Model 3: adjusted for sex, age, education, $\mathrm{HSI}$, and country; c Model was not adjusted for HSI; d OR and AOR for a model with the variable dichotomised into 'smokes within 5 min/all other' were comparable, but not significant. ${ }^{*} p$-values are for the overall model effect of the variable cigarette flavour in each model. 


\section{DISCUSSION}

This cross-sectional multi-country study is among the first to explore flavoured cigarette smoking and cessation patterns, behaviours, quitting motivation and self-efficacy among European MFC smokers. The preference for flavoured cigarettes, and particularly menthol cigarettes, was significantly associated with lower smoking dependence, higher quitting selfefficacy, having made an attempt to quit in the past 12 months, having used any cessation aids, and ever use of e-cigarettes, after we accounted for sociodemographic and dependence characteristics. However, part of this association was accounted for by the country, since its inclusion in the model attenuated the association between cigarette flavours and cessation behaviours. Since many of the characteristics of menthol cigarette smokers are associated with quitting behaviours and success, these results suggest that the upcoming EUwide TPD ban on additives may create an opportunity for increased cessation rates, but not all countries may see the same degree of benefit.

Smokers of different flavoured cigarettes were not a homogeneous group and were characterised by different levels of dependence levels, prior cessation behaviours as well as quitting self-efficacy. These differences are also consistent with findings from earlier analyses based on the same dataset, which demonstrated differences in the sociodemographic profile of smokers of menthol and other flavoured cigarettes, as well as their attitudes towards tobacco control measures ${ }^{13}$.

Importantly, compared to smokers of unflavoured tobacco, smokers of menthol cigarettes tended to be significantly less nicotine dependent, including as assessed with time to first cigarette (a good indicator of dependence for menthol cigarette smokers ${ }^{20}$ ) and viewed themselves as less heavily addicted. This is an important finding, as lower dependence is a consistent predictor of cessation success when quit attempts are made ${ }^{48,49}$. Interestingly, these findings are in contrast to many of the earlier observations on menthol smokers in the US suggesting similar ${ }^{22}$ or higher dependence levels ${ }^{14,17}$, which may also be contributing to greater difficulties with quitting among this group ${ }^{19,50-52}$. The difference in findings may be due to the fact that different brands of menthol cigarettes may contain different levels of nicotine, and the number of cigarettes smoked per day may not reflect the actual intensity of smoking and thus the actual nicotine intake $e^{6,19}$.
Additionally, social idiosyncrasies might also play a role in the US, where high levels of menthol smoking are concentrated almost entirely among minority populations, and in particular among African-American smokers, who are nearly 11 times more likely to use menthol cigarettes than White smokers ${ }^{53}$.

In unadjusted analyses, cigarette flavour was significantly associated with plans to quit, self-efficacy, and prior cessation behaviour. Menthol cigarette smokers tended to be more likely to plan to quit in the next 6 months, had higher self-efficacy, and engaged with more cessation-related behaviours, all of which are associated with future cessation success ${ }^{42,48,54}$. They also had higher odds of ever use of e-cigarettes. These observations suggest that menthol smokers in Europe might be more likely to succeed if they attempt to quit. However, while a ban on menthol and other flavourings could trigger a quit attempt, it could also lead to alternative behaviours undesirable from a tobacco control point of view. In fact, MFC smokers have declared a gamut of intentions following the ban, ranging from quitting or reducing the amount smoked, to switching to another brand, or even finding a way to get the banned product - with the latter two options indicated most frequently ${ }^{13}$.

Furthermore, many of the differences in plans to quit, self-efficacy, and cessation behaviours were diminished in the adjusted analyses, especially after controlling for country. Important differences exist between European countries in implementation of tobacco control measures and offering cessation support ${ }^{55,56}$. These differences affect opportunities of smokers to engage with evidence-based support and are also likely to influence smokers' cessation efforts, plans and selfefficacy ${ }^{57,58}$. Thus, while smokers of different flavoured cigarettes may differ on important characteristics related to smoking and cessation, the circumstances in their countries remain important predictors. Countries should implement best practice strategies in tobacco control and offer smoking cessation support.

The EU TPD ban on additives, including menthol and other flavourings, will have an impact on a significant minority of current smokers in Europe, of which menthol smokers are the largest group. The present findings show that smokers of menthol cigarettes demonstrate many characteristics that are positively associated with initiating quitting and remaining abstinent. Therefore, if menthol smokers 
are prompted to make a quit attempt, their success rates may be relatively higher ${ }^{48,59}$. Efforts at reducing smoking prevalence in countries such as England and Poland, where the proportion of MFC smokers is particularly high (almost 15\%), as well as among female smokers, among whom MFC use $(13.7 \%)$ is almost twice as high as among men, are particularly well placed to benefit from the ban ${ }^{13}$.

However, an earlier study assessing the plans of the same population of smokers in Europe in response to the TPD ban suggests that only a minority would consider quitting smoking due to the ban, and even more smokers are still not sure how they will react to the $\mathrm{ban}^{13}$. This study suggests that activities focused on supporting menthol smokers to initiate quitting during the implementation of the TPD ban on additives could increase cessation and lead to favourable public health outcomes. Such activities could be delivered by governmental and healthcare institutions, but also non-governmental organisations and charities. At the same time, the relationship between cessation behaviours and countries that emerged in this study provides an indication that the biggest challenges, but also opportunities for TPD ban on additives, will be in countries where smokers make fewer attempts, have lower motivation to quit, and use fewer cessation aids.

\section{Strengths and limitations}

This was the first study to comprehensively characterise the smoking and quitting behaviours and perceptions of MFC smokers in European countries. We were also able to compare these smokers on a range of characteristics that were shown to be associated with cessation behaviour and success in previous studies. However, the study has some limitations. First, the study was cross-sectional and thus precludes any causal interpretation of associations found. Future research will need to assess cessation behaviour and outcomes prospectively. Second, all respondents were current smokers, which precluded making comparisons between successful and unsuccessful quit attempts and assessing predictors of cessation outcomes. Third, the wording of survey questions did not allow for making a distinction between smokers who used menthol or other flavoured cigarettes predominantly or only in conjunction with unflavoured tobacco. Fourth, residual confounding due to unassessed or imperfectly measured confounders is possible, such as the duration of menthol cigarette use among the sample, which was shown previously to be associated with smoking and quitting behaviour ${ }^{26}$. Finally, there exist important differences in prevalence of use of different flavours of cigarettes ${ }^{13}$ and in cessation behaviour between European countries ${ }^{57}$, and interaction between variables may exist that pose challenges to interpreting the main effects. However, due to too few cases of menthol and flavoured cigarette users in each country, assessing such interactions is not possible. Future research should explore the differences between different tobacco users across countries.

\section{CONCLUSIONS}

In the eight European countries there seem to be important differences in the smoking and cessation profile, behaviours, and self-efficacy between smokers of menthol, flavoured, unflavoured tobacco, and those with no usual brand. The lower dependence levels among menthol and flavoured cigarette users is particularly encouraging as lower dependence is predictive of cessation success. In the light of the EU TPD ban on characterising flavours in tobacco products in the EU, tobacco control activities should focus on increasing quit attempts of menthol smokers, which could translate into greater cessation rates.

*EUREST-PLUS consortium members:

European Network on Smoking and Tobacco Prevention (ENSP), Belgium: Constantine I. Vardavas, Andrea Glahn, Christina N. Kyriakos, Dominick Nguyen, Katerina Nikitara, Cornel Radu-Loghin, Polina Starchenko University of Crete (UoC), Greece: Aristidis Tsatsakis, Charis Girvalaki, Chryssi Igoumenaki, Sophia Papadakis, Aikaterini Papathanasaki, Manolis Tzatzarakis, Alexander I. Vardavas

Kantar Public (TNS), Belgium: Nicolas Bécuwe, Lavinia Deaconu, Sophie Goudet, Christopher Hanley, Oscar Rivière

Smoking or Health Hungarian Foundation (SHHF), Hungary: Tibor Demjén, Judit Kiss, Piroska A. Kovács

Catalan Institut of Oncology (ICO); Bellvitge Biomedical Research Institute (IDIBELL), Spain: Esteve Fernández, Yolanda Castellano, Marcela Fu, Sarah 0. Nogueira, Olena Tigova

Kings College London (KCL), United Kingdom: Ann McNeill, Katherine East, Sara C. Hitchman

Cancer Prevention Unit and WHO Collaborating Centre for Tobacco Control, German Cancer Research Center (DKFZ), Germany: Ute Mons, Sarah Kahnert

National and Kapodistrian University of Athens (UoA), Greece: Yannis Tountas, Panagiotis Behrakis, Filippos T. Filippidis, Christina Gratziou, Paraskevi Katsaounou, Theodosia Peleki, Ioanna Petroulia, Chara Tzavara Aer Pur Romania, Romania: Antigona C. Trofor, Marius Eremia, Lucia Lotrean, Florin Mihaltan

European Respiratory Society (ERS), Switzerland; Goethe University Frankfurt, Germany: Gernot Rohde, Tamaki Asano, Claudia Cichon, Amy Far, Céline Genton, Melanie Jessner, Linnea Hedman, Christer Janson, Ann 
Lindberg, Beth Maguire, Sofia Ravara, Valérie Vaccaro, Brian Ward Maastricht University, the Netherlands: Marc Willemsen, Hein de Vries, Karin Hummel, Gera E. Nagelhout

Health Promotion Foundation (HPF), Poland: Witold A. Zatoński, Aleksandra Herbeć, Kinga Janik-Koncewicz, Krzysztof Przewoźniak, Mateusz Zatoński University of Waterloo (UW); Ontario Institute for Cancer Research, Canada: Geoffrey T. Fong, Thomas K. Agar, Pete Driezen, Shannon Gravely, Anne C. K. Quah, Mary E. Thompson

\section{REFERENCES}

1. Directive 2014/40/EU of the European Parliament and of the Council of 3 April 2014 on the approximation of the laws, regulations and administrative provisions of the Member States concerning the manufacture, presentation and sale of tobacco and related products and repealing Directive 2001/37/EC (Text with EEA relevance). http:// data.europa.eu/eli/dir/2014/40/2015-01-06. Accessed March 5, 2019.

2. Zatoński M. Evidence-based policy making? The case of Polish opposition to the EU Tobacco Products Directive. Journal of Health Inequalities. 2016;1:36-39. doi:10.5114/jhi.2016.61418

3. European Commission. Questions \& Answers: New rules for tobacco products. 2014. https://europa.eu/rapid/ press-release_MEMO-14-134_en.htm. Accessed March $5,2019$.

4. Okuyemi KS, Ebersole-Robinson M, Nazir N, Ahluwalia JS. African-American menthol and nonmenthol smokers: differences in smoking and cessation experiences. J Natl Med Assoc. 2004;96(9):1208-1211. PMID:15481749.

5. Villanti AC, Mowery PD, Delnevo CD, Niaura RS, Abrams DB, Giovino GA. Changes in the prevalence and correlates of menthol cigarette use in the USA, 2004-2014. Tob Control. 2016;25(Suppl 2):ii14-ii20. doi:10.1136/tobaccocontrol-2016-053329

6. Muscat J, Richie J, Stellman S. Mentholated cigarettes and smoking habits in whites and blacks. Tob Control. 2002;11(4):368-371. doi:10.1136/tc.11.4.368

7. Rose SW, Sherry EL, Ennett S, McNaughton Reyes HL, Scott JC, Kurt RM. Public Support for Family Smoking Prevention and Tobacco Control Act Point-of-Sale Provisions: Results of a National Study. Am J Public Health. 2015;105(10):e60-e67. doi:10.2105/ajph.2015.302751

8. O'Connor RJ, Bansal-Travers M, Carter LP, Cummings KM. What would menthol smokers do if menthol in cigarettes were banned? Behavioral intentions and simulated demand. Addiction. 2012;107(7):1330-1338. doi:10.1111/j.1360-0443.2012.03822.x

9. Feirman SP, Lock D, Cohen JE, Holtgrave DR, Li T. Flavored Tobacco Products in the United States: A Systematic Review Assessing Use and Attitudes. Nicotine Tob Res. 2016;18(5):739-749. doi:10.1093/ntr/ntv176

10. Wackowski OA, Manderski MT, Delnevo CD. Young Adults' Behavioral Intentions Surrounding a Potential Menthol Cigarette Ban. Nicotine Tob Res. 2014;16(6):876-80. doi:10.1093/ntr/ntu003
11. Kaleta D, Usidame B, Szosland-Fattyn A, MakowiecDąbrowska T. Use of flavoured cigarettes in Poland: data from the global adult tobacco survey (2009-2010). BMC Public Health. 2014;14:127. doi:10.1186/1471-2458-14-127

12. Fong GT, Thompson ME, Boudreau C, et al. The Conceptual Model and Methods of Wave 1 ( 2016 ) of the EUREST-PLUS ITC 6 European Countries Survey. Tob Induc Dis. 2018;16(Suppl 2:A3). doi:10.18332/tid/99881

13. Zatoński M, Herbeć A, Zatoński W, et al. Characterising smokers of menthol and flavoured cigarettes, their attitudes towards tobacco regulation, and the anticipated impact of the Tobacco Products Directive on their smoking and quitting behaviours: The EUREST-PLUS ITC Europe Surveys. Tob Induc Dis. 2018;16(Suppl 2:A4). doi:10.18332/tid/96294

14. World Health Organization. Banning menthol in tobacco products: Study Group on Tobacco Product Regulation (TobReg). Geneva, Switzerland: World Health Organization; 2016. https://apps.who.int/iris/ bitstream/handle/10665/205928/9789241510332_ eng.pdf; jsessionid=F8E52152FDD0F8F DCDB04C 8F734DB8DB? sequence=1. Accessed March 5, 2019.

15. The influence of the availability of menthol cigarettes on youth smoking prevalence. Oxford Economics. 2012. https://assets.publishing.service.gov.uk/government/ uploads/system/uploads/attachment_data/file/229776/ DE795779_Attachment_2_-_Oxford_Economics_The_ influence_of_the_availability_of_ment.pdf. Accessed March 5, 2019.

16. Stahre M1, Okuyemi KS, Joseph AM, Fu SS. Racial/ethnic differences in menthol cigarette smoking, population quit ratios and utilization of evidence-based tobacco cessation treatments. Addiction. 2010;105(Suppl 1):7583. doi:10.1111/j.1360-0443.2010.03200.x

17. Hersey JC, Wen NS, Nonnemaker J, et al. Are Menthol Cigarettes a Starter Product for Youth? Nicotine Tob Res. 2006;8(3):403-413. doi:10.1080/14622200600670389

18. Kasza KA, Hyland AJ, Bansal-Travers M, et al. Switching between menthol and nonmenthol cigarettes: findings from the U.S. Cohort of the International Tobacco Control Four Country Survey. Nicotine Tob Res. 2014;16(9):1255-1265. doi:10.1093/ntr/ntu098

19. Foulds J, Hooper MW, Pletcher MJ, Okuyemi KS. Do smokers of menthol cigarettes find it harder to quit smoking? Nicotine Tob Res. 2010;12(Suppl 2):S102-109. doi: $10.1093 / \mathrm{ntr} / \mathrm{ntq} 166$

20. Hoffman AC, Simmons D. Menthol cigarette smoking and nicotine dependence. Tob Induc Dis. 2011;9(Suppl 1:S5). doi:10.1186/1617-9625-9-S1-S5

21. Yerger VB. Menthol's potential effects on nicotine dependence: a tobacco industry perspective. Tob Control. 2011;20(Suppl 2):ii29-ii36. doi:10.1136/tc.2010.041970

22. Curtin GM, Sulsky SI, Van Landingham C, et al. Primary measures of dependence among menthol compared to non-menthol cigarette smokers in the United States. 
Regul Toxicol Pharmacol. 2014;69(3):451-466. doi:10.1016/j.yrtph.2014.05.011

23. Kreslake JM, Wayne GF, Alpert HR, Koh HK, Connolly GN. Tobacco industry control of menthol in cigarettes and targeting of adolescents and young adults. Am J Public Health. 2008;98(9):1685-1892. doi:10.2105/AJPH.2007.125542

24. Anderson SJ. Menthol cigarettes and smoking cessation behaviour: a review of tobacco industry documents. Tob Control. 2011;20(Suppl 2):ii49-ii56. doi:10.1136/tc.2010.041947

25. Richardson A, Ganz O, Pearson J, Celcis N, Vallone D, Villanti AC. How the industry is marketing menthol cigarettes: the audience, the message and the medium. Tob Control. 2015;24(6):594-600. doi:10.1136/tobaccocontrol-2014-051657

26. Kreslake J, Wayne GF, Connolly G. The menthol smoker: tobacco industry research on consumer sensory perception of menthol cigarettes and its role in smoking behavior. Nicotine Tob Res. 2008;10(4):705-715. doi:10.1080/14622200801979134

27. Fong GT, Cummings KM, Borland R, et al. The conceptual framework of the International Tobacco Control (ITC) Policy Evaluation Project. Tob Control. 2006;15(Suppl 3):iii3-iii11. doi:10.1136/tc.2005.015438

28. ITC Project. ITC 6 European Country Wave 1 (2016) Technical Report. University of Waterloo, Waterloo, Ontario, Canada, and European Network on Smoking and Tobacco Prevention, Brussels, Belgium; 2017. https:// itcproject.org/files/ITC6E_Wave1_TechRpt[3].pdf. Accessed March 5, 2019.

29. Vardavas CI, Bécuwe N, Demjén T, et al. Study Protocol of European Regulatory Science on Tobacco (EURESTPLUS): Policy implementation to reduce lung disease. Tob Induc Dis. 2018;16(Suppl 2:A2). doi:10.18332/tid/93305.

30. ITC Project. ITC Four Country Smoking and Vaping Survey, Wave 1 (4CV1) Technical Report. University of Waterloo, Waterloo, Ontario, Canada, and European Network on Smoking and Tobacco Prevention, Brussels, Belgium; 2017. http://www.itcproject.org/files/4CV1_Technical_ Report_20July2018.pdf. Accessed March 5, 2019.

31. ITC Project. Nertherlands. 2014. http://www.itcproject. org/countries/netherlands. Accessed March 5, 2019.

32. ITC Project. ITC Netherlands Survey Wave 1 to 8 (2008-2014) Technical Report. University of Waterloo, Waterloo, Ontario, Canada and Maastricht University, The Netherlands; 2015. https://www.itcproject.org/files/ITC_ NLWaves1-8TechReport-v2.pdf. Accessed March 5, 2019.

33. Thompson ME, Fong GT, Hammond D, et al. Methods of the International Tobacco Control (ITC) Four Country Survey. Tob Control. 2006;15(Suppl 3):iii12-iii18. doi:10.1136/tc.2005.013870

34. ITC Project. Evaluating How Tobacco Control Policies are Shaping the Nicotine Delivery Market. 2014. http:// www.itcproject.org/node/152. Accessed March 5, 2019.
35. Thompson ME, Fong GT, Boudreau C, et al. Methods of the ITC Four Country Smoking and Vaping Survey, wave 1 (2016). Addiction. 2018. doi:10.1111/add.14528

36. Nagelhout GE, Willemsen MC, Thompson ME, Fong GT, van den Putte $B$, de Vries $H$. Is web interviewing a good alternative to telephone interviewing? Findings from the International Tobacco Control (ITC) Netherlands survey. BMC Public Health. 2010;10(1):351. doi:10.1186/1471-2458-10-351

37. Zethof D, Nagelhout GE, de Rooij M, et al. Attrition analysed in five waves of a longitudinal yearly survey of smokers: findings from the ITC Netherlands survey. Eur J Public Health. 2016;26(4):693-699. doi:10.1093/eurpub/ckw037

38. Etter JF, Duc TV, Perneger TV. Validity of the Fagerstrom test for nicotine dependence and of the Heaviness of Smoking Index among relatively light smokers. Addiction, 1999;94(2):269-281. doi:10.1046/j.13600443.1999.94226910.x

39. Borland R, Partos TR, Yong HH, Cummings KM, Hyland A. How much unsuccessful quitting activity is going on among adult smokers? Data from the International Tobacco Control Four Country cohort survey. Addiction. 2012;107(3):673-382. doi:10.1111/j.1360-0443.2011.03685.x

40. Hummel K, Brown J, Willemsen MC, West R, Kotz D. External validation of the Motivation To Stop Scale (MTSS): findings from the International Tobacco Control (ITC) Netherlands Survey. Eur J Public Health. 2017;27(1):129-134. doi:10.1093/eurpub/ckw105

41. Marques-Vidal P, Melich-Cerveira J, Paccaud F, Waeber G, Vollenweider P, Cornuz J. Prevalence and factors associated with difficulty and intention to quit smoking in Switzerland. BMC Public Health. 2011;11(1):227. doi:10.1186/1471-2458-11-227

42. Gwaltney CJ, Metrik J, Kahler CW, Shiffman S. Selfefficacy and smoking cessation: a meta-analysis. Psychol Addict Behav. 2009;23(1):56-66. doi:10.1037/a0013529

43. Borland R, Yong HH, Balmford J, et al. Motivational factors predict quit attempts but not maintenance of smoking cessation: findings from the International Tobacco Control Four country project. Nicotine Tob Res. 2010;12(Suppl 1):S4-S11. doi:10.1093/ntr/ntq050

44. Siahpush M, Borland R, Yong HH. Sociodemographic and psychosocial correlates of smoking-induced deprivation and its effect on quitting: findings from the International Tobacco Control Policy Evaluation Survey. Tob Control. 2007;16(2):e2. doi:10.1136/tc.2006.016279

45. Waters EA, Janssen E, Kaufman A, et al. The Relationship Between Young Adult Smokers' Beliefs About Nicotine Addiction and Smoking-Related Affect and Cognitions. J Cancer Educ. 2016;31(2):338-347. doi:10.1007/s13187-015-0819-y

46. Duffy SA, Scheumann AL, Fowler KE, Darling-Fisher C, Terrell JE. Perceived difficulty quitting predicts 
enrollment in a smoking-cessation program for patients with head and neck cancer. Oncol Nurs Forum. 2010;37(3):349-356. doi:10.1188/10.onf.349-356

47. Kyriakos C, Filippidis F, Hitchman S, et al. Characteristics and correlates of electronic cigarette product attributes and undesirable events during e-cigarette use in six countries of the EUREST-PLUS ITC Europe Surveys. Tob Induc Dis. 2018;16(Suppl 2:A1). doi:10.18332/tid/93545

48. Hyland A, Borland R, Li Q, et al. Individual-level predictors of cessation behaviours among participants in the International Tobacco Control (ITC) Four Country Survey. Tob Control. 2006;15(Suppl 3):iii83-iii94. doi:10.1136/tc.2005.013516

49. Ussher M, Kakar G, Hajek P, West R. Dependence and motivation to stop smoking as predictors of success of a quit attempt among smokers seeking help to quit. Addict Behav. 2016;53:175-180. doi:10.1016/j.addbeh.2015.10.020

50. Levy DT, Blackman K, Tauras J, et al. Quit attempts and quit rates among menthol and nonmenthol smokers in the United States. Am J Public Health. 2011;101(7):12411247. doi:10.2105/ajph.2011.300178

51. Keeler C, Max W, Yerger V, Yao T, Ong MK, Sung HY. The Association of Menthol Cigarette Use With Quit Attempts, Successful Cessation, and Intention to Quit Across Racial/ Ethnic Groups in the United States. Nicotine Tob Res. 2017;19(12):1450-1464. doi:10.1093/ntr/ntw215

52. Smith SS, Fiore MC, Baker TB. Smoking cessation in smokers who smoke menthol and non-menthol cigarettes. Addiction. 2014;109(12):2107-2117. doi:10.1111/add.12661

53. Lawrence D, Rose A, Fagan P, Moolchan ET, Gibson JT. National patterns and correlates of mentholated cigarette use in the United States. Addiction. 2010;105:13-31. doi:10.1111/j.1360-0443.2010.03203.x

54. Smit ES, Hoving C, Schelleman-Offermans K, West R, de Vries H. Predictors of successful and unsuccessful quit attempts among smokers motivated to quit. Addict Behav. 2014;39(9):1318-1324. doi:10.1016/j.addbeh.2014.04.017

55. Herbeć A, McEwen A, West R, Zatoński WA. Development and evaluation of STAR - an expert digital platform supporting training and delivery of cessation interventions by healthcare professionals in Poland. Tob Prev Cessation. 2017;3(May Supplement):133-137. doi:10.18332/tpc/71170

56. Feliu A, Filippidis F, Joossens L, et al. Impact of tobacco control policies on smoking prevalence and quit ratios in 27 European Union countries from 2006 to 2014. Tob Control. 2019;28(1):101-109. doi:10.1136/tobaccocontrol-2017-054119

57. Hummel K, Nagelhout G, Fong GT, et al. Quitting activity and use of cessation assistance reported by smokers in eight European countries: Findings from the EURESTPLUS ITC Europe Surveys. Tob Induc Dis. 2018;16(Suppl 2:A6). doi:10.18332/tid/98912

58. Hummel K, Nagelhout GT, Willemsen MC, et al.
Trends and socioeconomic differences in policy triggers for thinking about quitting smoking: Findings from the International Tobacco Control (ITG) Europe Surveys. Drug Alcohol Depend. 2015;155:154-162. doi:10.1016/j.drugalcdep.2015.07.678

59. Vangeli E, Stapleton J, Smit ES, Borland R, West R. Predictors of attempts to stop smoking and their success in adult general population samples: a systematic review. Addiction. 2011;106(12):2110-2121. doi:10.1111/j.1360-0443.2011.03565.x

ACKNOWLEDGEMENTS

The EUREST-PLUS Project takes place with the financial support of the European Commission, Horizon 2020 HCO-6-2015 programme (EURESTPLUS: 681109; CV) and the University of Waterloo (GTF). Additional support was provided to the University of Waterloo by the Canadian Institutes of Health Research (FDN-148477). GTF was supported by a Senior Investigator Grant from the Ontario Institute for Cancer Research. EF was supported by the Instituto de Salud Carlos III, Government of Spain (INT16/00211 and INT17/00103), co-funded by the European Regional Development Fund (FEDER), and by Ministry of Universities and Research, Government of Catalonia (2017SGR319). The Wave 1 of the ITC 4 Country E-cigarette Project in England was supported by grant P01 CA200512-01 from the National Cancer Institute of the USA, and a Foundation Grant (118096) from the Canadian Institute of Health Research. The Wave 10 of the Netherlands Project was supported by the Dutch Cancer Foundation (KWF) (UM 2014-7210). Partnering organizations include the European Network on Smoking Prevention (Belgium), Kings College London (United Kingdom), German Cancer Research Centre (Germany), Maastricht University (The Netherlands), National and Kapodistrian University of Athens (Greece), Aer Pur Romania (Romania), European Respiratory Society (Switzerland), the University of Waterloo (Canada), The Institute Català d'Oncologia (Spain), Smoking or Health Hungarian Foundation (Hungary), Health Promotion Foundation (Poland), University of Crete (Greece), and Kantar Public Brussels (Belgium).

\section{CONFLICTS OF INTEREST}

The authors declare that they have no competing interests, financial or otherwise, related to the current work. K. Przewoźniak reports grants and personal fees from the Polska Liga Walki z Rakiem (Polish League Against Cancer) and grants and personal fees from World Health Organization, outside the submitted work. C.I. Vardavas reports that he is the Strategic Development Editor of TID and that there are no conflicts of interest with this current work. The rest of the authors have also completed and submitted an ICMJE form for disclosure of potential conflicts of interest.

\section{FUNDING}

The EUREST-PLUS project has received funding from the European Union's Horizon 2020 research and innovation programme under grant agreement No 681109 (C.I.V.) and the University of Waterloo (G.T. Fong). Additional support was provided to the University of Waterloo by the Canadian Institutes of Health Research (FDN-148477). G.T. Fong was supported by a Senior Investigator Grant from the Ontario Institute for Cancer Research. E. Fernández is partly supported by Ministry of Universities and Research, Government of Catalonia (2017SGR319) and by the Instituto Carlos III and co-funded by the European Regional Development Fund (FEDER) (INT16/00211 and INT17/00103), Government of Spain.

\section{PROVENANCE AND PEER REVIEW}

Commissioned; externally peer reviewed. 